Supporting Information

\title{
A Low-Cost Ni-Mn-Ti-B High-Temperature Shape Memory Alloy with Extraordinary Functional Properties
}

\author{
Shaohui Li ${ }^{\text {a }}$, Daoyong Cong ${ }^{\mathrm{a}, *}$, Wenxin Xiong ${ }^{\mathrm{a}}$, Zhen Chen ${ }^{\mathrm{a}}$, Xin Zhang ${ }^{\mathrm{b}}$, \\ Zhihua Nie ${ }^{\mathrm{c}}$, Shengwei $\mathrm{Li}^{\mathrm{a}}$, Runguang $\mathrm{Li}^{\mathrm{a}}$, Youkang Wang ${ }^{\mathrm{a}}$, Yuxian Cao ${ }^{\mathrm{a}}$, \\ Yang Ren ${ }^{\mathrm{d}}$, Yandong Wang ${ }^{\mathrm{a}}$ \\ ${ }^{a}$ Beijing Advanced Innovation Center for Materials Genome Engineering, State Key \\ Laboratory for Advanced Metals and Materials, University of Science and Technology \\ Beijing, Beijing 100083, China \\ ${ }^{b}$ Tianjin Key Laboratory of Materials Laminating Fabrication and Interface Control \\ Technology, Hebei University of Technology, Tianjin 300130, China \\ ${ }^{c}$ School of Materials Science and Engineering, Beijing Institute of Technology, Beijing \\ 100081, China \\ ${ }^{d}$ X-ray Science Division, Argonne National Laboratory, Argonne, IL 60439, USA
}

*Corresponding Author. E-mail address: dycong@,ustb.edu.cn (Daoyong Cong) 

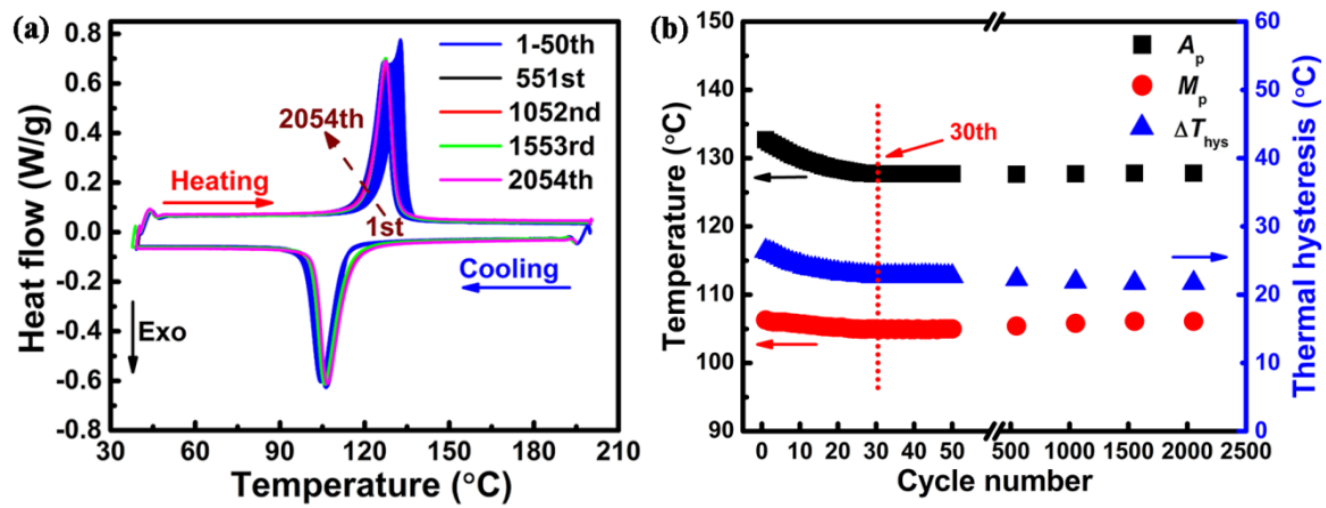

Figure S1. (a) DSC curves recorded during different cycles of cooling and heating (with a rate of $\left.10{ }^{\circ} \mathrm{C} / \mathrm{min}\right)$ for the $\left(\mathrm{Ni}_{50} \mathrm{Mn}_{35.5} \mathrm{Ti}_{14.5}\right)_{99.8} \mathrm{~B}_{0.2}$ alloy. The dashed arrow indicates the direction of increasing cycle number. The maximum cycle number is 2054. (b) Peak temperature for martensitic transformation $\left(M_{\mathrm{p}}\right)$, peak temperature for reverse transformation $\left(A_{\mathrm{p}}\right)$ and thermal hysteresis $\left(\Delta T_{\mathrm{hys}}\right)$ as a function of cycle number. 

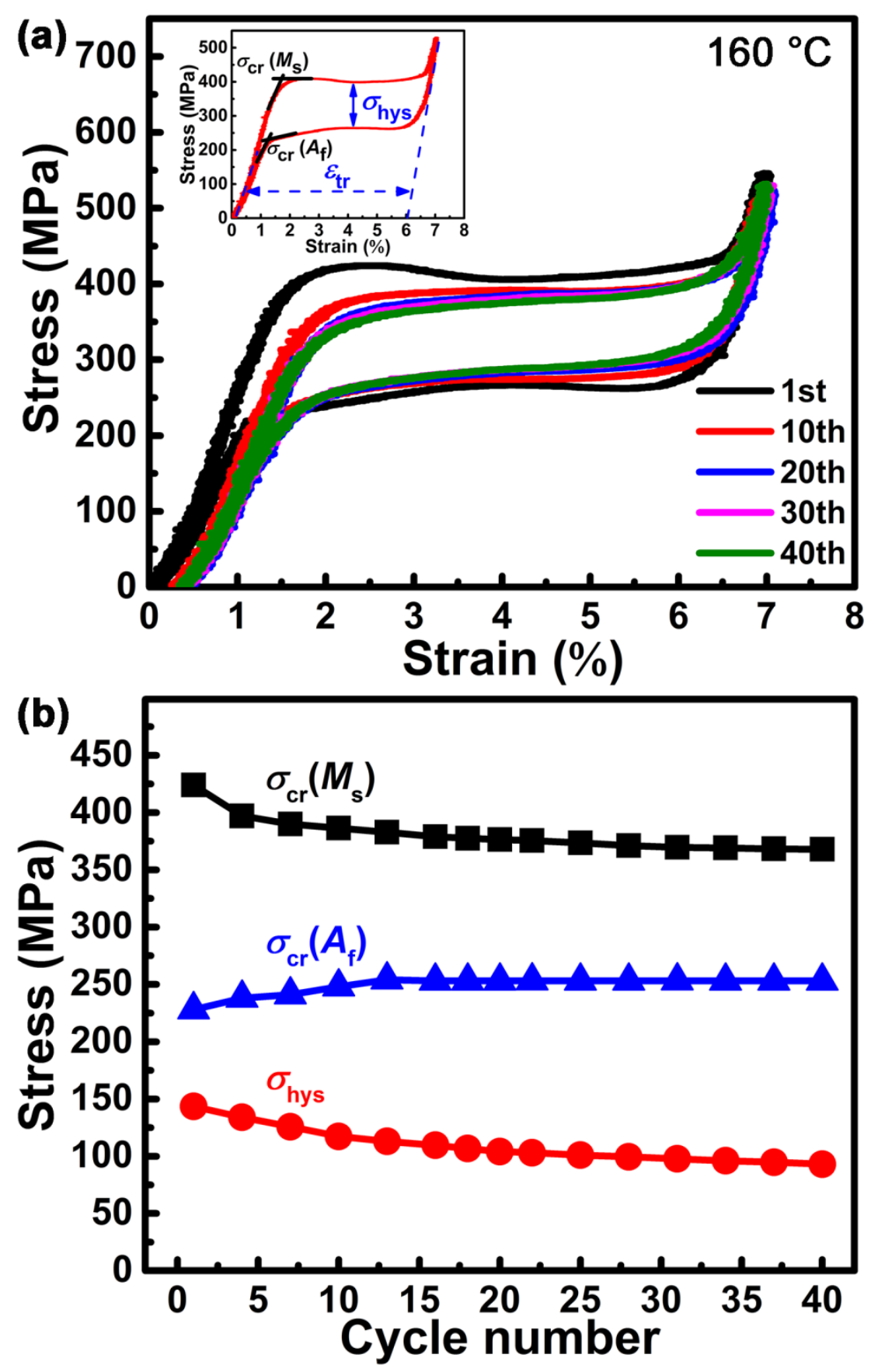

Figure S2. (a) Superelastic stress-strain curves measured during 40 cycles of loading and unloading at $160{ }^{\circ} \mathrm{C}$, for the $\left(\mathrm{Ni}_{50} \mathrm{Mn}_{35.5} \mathrm{Ti}_{14.5}\right)_{99.8} \mathrm{~B}_{0.2}$ alloy. The determination of stress hysteresis $\sigma_{\text {hys }}$, transformation strain $\varepsilon_{\text {tr }}$ and critical stresses for the start of stress-induced martensitic transformation $\left[\sigma_{\mathrm{cr}}\left(M_{\mathrm{s}}\right)\right]$ and the finish of reverse transformation $\left[\sigma_{\mathrm{cr}}\left(A_{\mathrm{f}}\right)\right]$ is illustrated in the inset. (b) Evolution of $\sigma_{\mathrm{cr}}\left(M_{\mathrm{s}}\right), \sigma_{\mathrm{cr}}\left(A_{\mathrm{f}}\right)$ and stress hysteresis $\sigma_{\text {hys }}$ with increasing cycle number. 

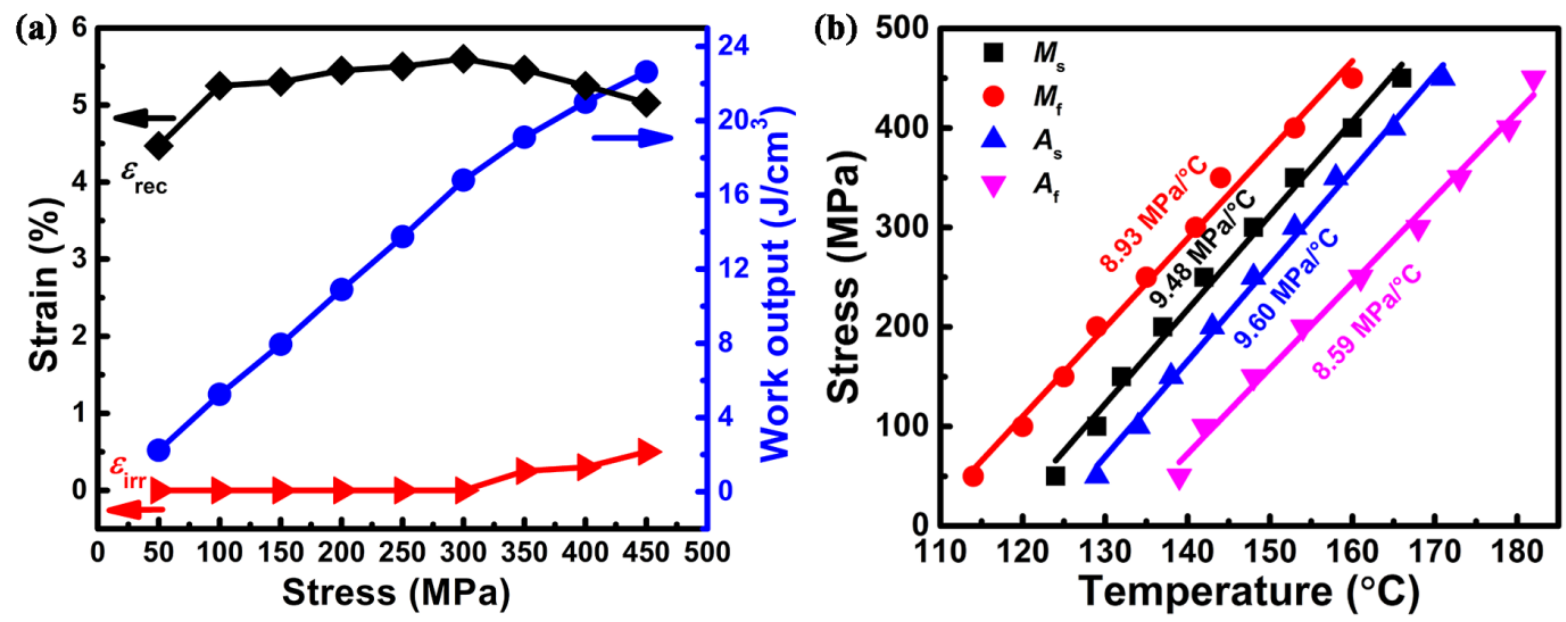

Figure S3. (a) Recoverable strain $\varepsilon_{\text {rec }}$, irrecoverable strain $\varepsilon_{\text {irr }}$ (left axis) and work output (right axis) as a function of applied stress for the $\left(\mathrm{Ni}_{50} \mathrm{Mn}_{35.5} \mathrm{Ti}_{14.5}\right)_{99.8} \mathrm{~B}_{0.2}$ alloy. (b) Stress-temperature phase diagram for the $\left(\mathrm{Ni}_{50} \mathrm{Mn}_{35.5} \mathrm{Ti}_{14.5}\right)_{99.8} \mathrm{~B}_{0.2}$ alloy. The transformation temperature $M_{\mathrm{s}}, M_{\mathrm{f}}, A_{\mathrm{s}}$, and $A_{\mathrm{f}}$ are extracted from the strain-temperature curves (shown in Figure 7) recorded during load-biased thermal cycling under different stresses. 